Aim Crises are frightening especially near the end of life. Primary care teams are pivotal in caring for patients in the final years of life, enabling more to live well and die where they choose, and reduce inappropriate crises and hospitalisation. With increasing pressures from the ageing population, rising mortality and limited resources, a more proactive approach to meeting these challenges is required.

The Gold Standards Framework (GSF) Quality Improvement Programme has been influential in EOLC since 2000 with most UK general practitioners using GSF foundation principles. We report on the findings of the first 17 GP practices undertaking GSF Going for Gold training and accreditation with some reaccredited three years later, demonstrating what is possible to achieve.

Method Primary care teams undertake a practice-based distance-learning GSF Gold programme with optional interactive workshops over 6-12 months. Evaluations before and after in preparation for accreditation include key outcome ratios, online After Death Analysis plus submission of a portfolio of evidence and assessment interview.

Results Cumulated findings for the accredited practices show significant improvements, including some reaccredited three years later demonstrating long-term sustainability. Practices demonstrate enhanced proactive end-of-life care, with earlier identification of over $60 \%$ of their patients who died, offering ACP discussions to over $65 \%$, leading to more home deaths and improved outcomes for patients and carers.

Conclusion Improving care for people in their last year of life in GP Practices with proactive person-centred care is pivotal to meeting the challenges of the ageing population, and making best use of limited resources. The GSF Gold programme reported here, is an example of a practical, well-received evidence-based quality improvement, leading to more proactive planned care in line with peoples' preferences, meeting the increasing needs of the ageing population.

\section{P-272 SUCCESSFUL SHARING OF MEDICAL EXPERTISE}

1,2Debbie Talbot, ${ }^{1,2}$ Sarah Mimmack. 'Birmingham St Mary's Hospice, Birmingham, UK; ${ }^{2} J o h n$ Taylor Hospice, Birmingham, UK

10.1136/bmispcare-2017-hospice.297

Background Two hospice organisations, serving the majority of the population of a major UK city (Hospice A and B). Hospice $B$ has been unsuccessful over several years, at recruiting into a substantive Consultant role. Medical staffing, was therefore identified as a potential area for joint working, that would improve patient experience and promote collaboration.

Aim Both organisations agreed that the Medical Director at Hospice A, would provide some clinical leadership to Hospice B.

Methods Medical Director job plan split between the two units (with backfill funded by Hospice B)

Initial objectives agreed:

- Review existing medical staffing and make recommendations around future workforce planning, including how to optimise chances of recruitment into consultant post(s)

- Identify opportunities for the hospices to work together more, especially around shared job roles and clinical redesign projects

- Lead a joint hospice initiative, to effect system -wide change for EOLC across the city.
Achievement against these objectives will be assessed at appraisal.

Results Recommendations around Hospice B medical staffing, included formally linking the Consultant post with Hospice A, making optimal use of peer support and existing CPD opportunities. Consultant body agreed to amalgamate second on-call services, for more efficient out of hours working. Revised job description approved by RCP - recruitment pending. Joint clinical working provoked wider sharing of resources such as policies, guidelines, education material etc and heightened efficiency around clinical governance. Both organisations are now scoping joint working around support functions such as IT. Combined senior clinical staff away day, identified priorities for influencing at regional and national level. Future EOLC stakeholder events scheduled.

Conclusions Good example of a joint clinical role, becoming a conduit for greater cooperation between neighbouring organisations. There have been benefits to both, including reputational. Most notably, however, patient care has been positively impacted, with less staff time being expended on duplicating efforts.

\section{P-273 MORE EFFECTIVE TOGETHER: PUTTING OUR HEADS TOGETHER TO INNOVATE AND LEAD}

Karen Causton, Nicola Button, Laura Shukla, Kathryn Davies. St Helena Hospice, Colchester, UK

\subsection{6/bmjspcare-2017-hospice.298}

Background The clinical heads of departments within our hospice had traditionally been located with their own teams, working in relative isolation. Budgets were managed individually, and often relatively small amounts of money were left unutilised. Clinical Heads did not always have a business background or expertise in this area.

Aims To share best practice, move away from silo working, utilise resources and encourage greater collaboration between the departmental heads.

Approach Help the Hospices' (2013) 'Future ambitions for hospice care; our mission and our opportunity' document recommends that hospices will be stronger in the future if attention is given to succession planning and developing leaders for the future. Furthermore, Hospice UK (2017) recommends that best practice is valued and shared, by combining expertise with business intelligence. One of the identified ways to achieve this, was to relocate the clinical heads of departments into an office together where they were joined by the newly appointed Head of Business, to facilitate coordinated working across teams. Positive feedback from members of our respective teams, our directors and visiting clinical heads from other hospices, has led us to believe that the approach is an innovative one.

Outcomes Joining the forces of clinical expertise and business acumen has provided collaborative leadership across Patient and Family Services and has generated the following benefits: joint strategic planning, inter-departmental budget setting, sharing of resources, joint KPI setting and performance monitoring. An example of this, is that combining left-over budgets from the three teams, which would otherwise have been left unspent, allowed a social worker to be employed to work across the organisation. 
Conclusion Our experience has shown that for the future sustainability of our hospice, this way of working must continue, as we become increasingly reliant on each other. Our recommendation is that collaborative leadership will deliver the ambitions to reach and support more people.

\section{P-274 A HOSPICE LEADERSHIP PIPELINE}

John Knight. LOROS Hospice, Leicester, UK

\subsection{6/bmispcare-2017-hospice.299}

The concept of a 'leadership pipeline' isn't something new (Charan, Drotter, \& Noel, 2001), however, its application to the evolving world of 'hospice' may well be. The pipeline model investigates how we best prepare people for an organisational leadership journey ensuring that they are equipped with and practice leadership skills, well in advance, of any promotion in the organisation. In 2014, following the Hospice UK 'Ambitions' publication, LOROS Hospice set about developing its own leadership pipeline confident of its impact internally and hopeful that it could be of value across the sector. Research shows that several factors influence the development and ongoing practice of leadership. Early exposure to leadership opportunities, learning through 'doing', reflecting upon role models and finally being embedded in a supportive culture are perhaps the main factors noted. Using this knowledge LOROS has developed two leadership interventions. Both are focussed upon 'self' - with the sole aim of helping aspirant and existing leaders invest time to better understand what they personally bring to leadership and just how they impact upon others and how others impact upon them. LOROS believes that this approach, 'to first understand oneself', is a fundamental in effective leadership development and should come before any other form of leadership programme that develops more technical skills such as financial or strategic leadership. 'Aspiring Leaders' is aimed at those new to leadership. It forms an intensive period of time where delegates are challenged to think about how and why they have come to a leadership position and how they wish to be viewed as a leader - nurturing their authentic leadership style. 'Thoughtful Leadership' is aimed at middle management leaders and delves deeper in to their own performance adding skills in managing challenging situations and the impact of coaching as a leadership tool.

\section{P-275 INSPIRING LEADERSHIP LEADING SELF: LEADING WITH OTHERS IN A PALLIATIVE CARE SETTING}

${ }^{1}$ Fiona Wylie, ${ }^{1,2}$ Claire O'Neill, ${ }^{1,3}$ Jane Miller, ${ }^{3}$ Susan Jackson. ${ }^{1}$ Prince and Princess of Wales Hospice, Glasgow, UK; ${ }^{2}$ NHS Greater Glasgow and Clyde Healthboard, Glasgow, UK; ${ }^{3}$ Action for Continuing Care Over Renfrew District (ACCORD) Hospice, Paisley, UK

\subsection{6/bmjspcare-2017-hospice.300}

Background It is recognised within palliative care (PC) that Band 6 Clinical Nurse Specialists (CNS) are working in a time of organisational change with increasing complexity around their specialist role (NHS Education for Scotland 2006). CNSs, in particular newly appointed staff, have reported feeling more vulnerable and stressed and struggling to cope to deliver the same quality of care to patients and their families. To support the above scenario an NHSGGC PC Leadership Steering Group was established in partnership with NES Leadership Unit.

Aims

- Provide a safe space for participants to share and learn from each other

- Provide a training programme which embeds the values, behaviours and attitudes of leadership skills

- Provide a foundation to support greater successional planning throughout palliative care (Scottish Government, 2013; Scottish Government, 2015)

- Increase participants' knowledge and understanding of quality improvement (QI) methodology supporting individual QI action plans.

Methods The development of a 12 month leadership programme based on needs of the participants, open to all Band 6 PC CNSs working within NHSGGC acute and hospice care settings, was established. The programme includes a leadership resource folder, ongoing staff support, feedback to participants utilising 360 degree review and Myers Briggs, provision of mentoring and action learning sets and evaluation process.

Results Interim feedback to date 10 CNSs signed up. To date participants have attended a launch day and two masterclasses held on: Understanding Myers Briggs and working with differences; Understanding Quality Improvement methodology.

All participants have received '360 review process' feedback based on the NHS Scotland Leadership Qualities Framework helping to inform their PDP. All have participated in an action learning set. Three further masterclasses are built around learning needs of the cohort.

Conclusion Feedback to date has highlighted the importance of this programme in addressing a need, focusing on developing leadership skills for a capable, sustainable workforce. Further evaluation is embedded within this programme.

\section{P-276 LEADING CHANGE, ADDING VALUE: POSITIONING NURSING, MIDWIFERY AND CARE STAFF AS LEADERS IN DRIVING CHANGE AND IMPROVING OUTCOMES}

Susan Aitkenhead, Stacey McCann. NHS England, Leeds, UK

\subsection{6/bmispcare-2017-hospice.301}

The presentation will outline the unique leadership role that nursing, midwifery and care staff have in driving change and improving outcomes. It will outline 'Leading Change, Adding Value: a framework for nursing, midwifery and care staff' that was launched in May 2016 by Professor Jane Cummings, Chief Nursing Officer for England. The framework positions nursing, midwifery and care staff as leaders in designing the future of health and care and managing the challenges of today. It explains how staff can demonstrate leadership in reducing the gaps of health and wellbeing, care and quality, and funding and efficiency, whatever their role wherever they work. The framework highlights the need to focus on quality and measurement, which aligns to the national priorities in England's Five Year Forward View - showing why change is needed and what it will look like. The focus is on reducing unwarranted variation, and delivering the 'Triple Aim' of improved outcomes, experience and better use of resources; the benchmarks for quality of services. Unwarranted variation is defined as differences that cannot be justified by geography, demography or infrastructure. The framework offers ten commitments that all staff can make. They align efforts to areas 